\title{
HUBUNGAN STATUS GIZI DENGAN DERAJAT HIPERTENSI PADA LANSIA DI DESA TOMBOLANGO KECAMATAN LOLAK
}

\author{
Ake Royke Calvin Langingi ${ }^{1}$ \\ Dosen S1 Keperawatan Institut Kesehatan dan Teknologi Graha Medika Kotamobagu \\ Alamat Korespondensi author: akelangingisister04@gmail.com
}

\begin{abstract}
Abstrak
Masalah gizi lansia adalah meningkat karena berbagai faktor seperti kurangnya pengetahuan tentang nutrisi lansia dan pemrosesan makanan yang baik untuk lansia yang kemudian langsung berefek status gizi lansia. Psikologis pengaruh, kesalahan diet, dan ekonomi rendah status keluarga juga dapat menyebabkan nutrisi yang tidak memadai di kalangan lansia. 4 Lansia dicirikan oleh kondisi unik mereka sebagai akibat dari perubahan fisiologis yang karakteristik penuaan, serta penyakit dan faktor psikososial dan diet yang mempengaruhi status gizi mereka. Hipertensi merupakan keadaan dimana tekanan darah yang sama atau melebihi $140 \mathrm{mmHg}$ sistolik dan/atau sama melebihi $90 \mathrm{mmHg}$ diastolik. Penelitian ini untuk mengetahui status gizi dengan derajat hipertensi pada lansia. Metode penelitian deskritif dengan pendekatan cross sectional. Total populasi 155 lansia dengan hipertensi dan didapat 32 Sampel. Instrument digunakan Lembar Observasi variabel independen adalah status gizi, variabel dependen adalah derajat hipertensi, Analisis menggunakan uji Chi Square. Hasil penelitian terdapat hubungan status gizi dengan derajat hipertensi pada lansia, yaitu di peroleh nilai $\mathrm{P}=0,003$ dimana nilai $\mathrm{p}$ lebih kecil dari $\mathrm{p}(0,05)$. Sebagai saran diharapkan, memberikan penyuluhan kesehatan kepada lansia untuk pengendalian status gizi yang seimbang, bagi masyarakat melakukan pencegahan dan penanggulangan hipertensi dengan cara memperbaiki pola makan dan mengurangi kebiasaan-kebiasaan yang dapat meningkatkan terjadinya hipertensi hipertensi. Kesimpulan dari penelitian ini adalah ada hubungan antara status gizi dengan derajat hipertensi pada lansia di Desa Tombolango kecamatan Lolak.
\end{abstract}

Kata Kunci: Hipertensi, Self-efficacy, Self-management behaviour

\begin{abstract}
Hypertension is one of chronic diseases and the main concern because of its high morbidity and mortality. Self-management behaviour has an important role to control blood pressure among hypertensive patients in effective way. Self-efficacy is the basic/main concept of self-management behaviour which give an impact to confidence of hypertensive patients. This study aimed to investigate the correlation between selfefficacy and self-management behaviour among hypertensive patients in Puskesmas III Denpasar Utara. This study was a correlational study with cross sectional design. Non-probability sampling with total sampling was used to recruit 61 hypertensive patients. The research instruments included Self-efficacy to Manage Hypertension-Five Item Scale and Hypertension Self-management Behaviour Questionnaire. In order to determine the correlation between self-efficacy and self-management behaviour, Spearman Rank was used because the data weren't normally distributed. The results of this study show that most of hypertensive patients have moderate level of self-management behaviour, while for self-efficacy have a bad level. Spearman Rank test shows the significant result with $p$-value $=0,000(p<0,05), r=0,794, R=63,04$, error level $5 \%$. In conclusion, there is a strong and positive correlation between self-efficacy and selfmanagement behaviour among hypertensive patients in Puskesmas III Denpasar Utara. Based on the result of this study, it is suggested to develop nursing intervention to improve self-efficacy among hypertensive patients to affect the self-management behaviour.
\end{abstract}

Keywords: Hypertension, Self-efficacy, Self-management behaviour 


\section{PENDAHULUAN}

Menurut World Health Organization (WHO) tahun 2018 bahwa tercatat 1 milyar orang di dunia menderita hipertensi dan diperkirakan terdapat 7,5 juta kematian atau sekitar $12,8 \%$ dari seluruh total kematian disebabkan oleh hipertensi. Menurut American Heart Associantion (2014), sekitar atau 1 dari 3 orang dewasa menderita penyakit ini. Bahkan diperkirakan akan terus meningkat $7,2 \%$ atau sekitar 83,5 juta orang pada tahun 2030 .

Menurut (WHO, 2013) Lanjut usia saat ini diseluruh dunia di perkirakan lebih dari 629 juta jiwa (Satu dari 10 orang berusia lebih dari 60 tahun), dan pada tahun 2025, lanjut usia diperkirakan mencapai 1,2 milyar. (Nonce, $\mathrm{N}, \mathrm{L}$, 2015). Berdasarkan Umur lanjut usia telah digolongkan menjadi empat yaitu (middle age) usia pertengahan 45-59 tahun, (elderly) lanjut usia 60-74 tahun, (old) lanjut usia tua 75-90 tahun, dan (very Old) usia sangat tua $>90$ tahun, penggolongan menurut WHO (2013).

Menurut Penelitian S.A Deji dkk (2014), penilaian status gizi dari kelompok hypertensive pasien menghadapi fasilitas kesehatan tertiary di nigeria. Bahwa sebagian besar pasien 52 (43,3\% di atas lima puluh usia lima tahun sedangkan mayoritas adalah perempuan $71(59 \%)$. Sebagian besar responden memiliki pendidikan tinggi 48 (40\%) sementara $92(76,6 \%)$ menikah. The riwayat medis pasien menunjukkan bahwa sebagian besar subyek $69 \quad(57,5 \%)$ telah didiagnosis hipertensi dalam satu tahun. Mayoritas, $75(62,5 \%)$ tidak memiliki riwayat keluarga hipertensi, sedangkan 82 (68\%) mengaku memiliki tekanan darah teratur pemeriksaan di rumah sakit. Sebagian besar 77 responden atau (64\%) didiagnosis hipertensi tanpa yang lain penyakit yang hidup berdampingan. Sekitar sepertiga dari pasien didiagnosis memiliki penyakit lain seperti diabetes 36 responden atau $(30 \%)$ dan jantung kegagalan enam (5\%) ada bersama dengan hipertensi. Paling pasien 72 (60\%) didiagnosis hipertensi selama pemeriksaan medis rutin. Kebiasaan asupan garam masih umum di kalangan pasien. Sedangkan mayoritas responden (85\%) melaporkan bahwa mereka masih dalam kebiasaan menambahkan garam memasak ke makanan mereka, $40 \%$ menyatakan itu mereka menggunakan sedikit garam dalam makanan mereka. Pengukuran antropometrik menunjukkan hal itu lebih banyak subjek wanita yang obesitas dan tidak ada pria kurang berat badan. Hanya 26,7\% responden dalam kisaran BMI (18.524.9) yang normal.

Menurut Penelitian Piyanit Churak, dkk (2018) Faktor yang terkait dengan status gizi lansia di Ubon Ratchathani, Thailand. Bahwa tiga ratus sembilan puluh delapan responden dimasukkan dalam analisis, di mana perempuan menjadi mayoritas subyek (258 peserta), $(64,8 \%)$. Di antara peserta perempuan ini, $55,0 \%$ diklasifikasikan sebagai lansia-muda (60 hingga 69 tahun) sedangkan 51,4\% adalah laki-laki lanjut usia. Prevalensi gangguan nafsu makan, jumlah makanan, dan status kesehatan yang dirasakan sendiri sebagai 'tidak baik' masing-masing adalah 31,9\%, $11,8 \%$ dan $24,9 \%$. Rata-rata BMI adalah $22,8 \pm 3,6 \mathrm{~kg} / \mathrm{m} 2$ untuk laki-laki dan $24,2 \pm 4,4 \mathrm{~kg} / \mathrm{m} 2$ untuk wanita. Saat mempertimbangkan subkelompok penuaan, hasil menunjukkan bahwa $18,5 \%$ pada wanita tua muda yang kurang berat badan, dan itu $81,5 \%$ pada lansia tua perempuan Untuk wanita yang kelebihan berat badan, $64,6 \%$ berada di kelompok usia 60-69 tahun, dan 35,4\% berada di kelompok usia 70 tahun ke atas. Proporsi pria dengan berat badan 
kurang tidak berbeda antara subkelompok umur dengan $47,1 \%$ pada kelompok yang lebih muda, dan $52,9 \%$ pada subkelompok yang lebih tua sedangkan laki-laki yang kelebihan berat badan adalah 55,9\% pada usia kelompok 60-69 tahun, dan $44,1 \%$ pada lansia yang berusia 70 tahun ke atas.

Menurut kementerian Kesehatan RI, lanjut usia dikelompokkan menjadi 3 kelompok, yaitu pra lanjut usia (45-59 tahun), lanjut usia (60-69 tahun), dan lanjut usia resiko tinggi $>60$ tahun atau usia > 70 tahun dengan masalah kesehatan. Menurut Data (Kemenkes RI, 2016). Hipertensi menempati urutan pertama pada masalah kesehatan lansia di Indonesia. Hipertensi juga salah satu penyakit yang paling tinggi, angka proportional mortality rate akibat hipertensi di seluruh dunia mencapai $13 \%$ atau 8 juta kematian setiap tahunnya (Anbarasan, 2015). Sebanyak 1 milyar lansia di dunia atau 1 dari 4 lanjut usia menderita hipertensi. Bahkan diperkirakan jumlah lansia yang menderita hipertensi akan meningkat menjadi 1,6 milyar menjelang tahun 2025. American society of hipertension melaporkan $1 / 3$ orang dewasa mengalami hipertensi di Negara maju dan berkembang (Bhandari, 2016). Sebagian besar penderita hipertensi berada di negara berkembang, termasuk Indonesia. (Nur A, Dkk 2018). Berdasarkan data RISKESDAS (2018) Prevalensi hipertensi di Indonesia Kalimantan (44,1\%), Jabar (43\%), Jateng (37,5\%), Jatim (37,5\%), Kaltim $(43,1 \%)$, Kalbar (38\%), Sumsel (32,7\%), Sulsel (32\%), Sultra (32,2\%), Sulbar (36\%), Sulteng (32,2\%), Gorontalo (32\%), Papua $(22,2 \%)$ dan prevalensi untuk provinsi sulut sebanyak (34\%).

Berdasarkan data RISKESDAS 2013 prevalensi status gizi penduduk dewasa ( $\geq 18$ tahun) berdasarkan kategori IMT.
Status gizi kurus $11,1 \%$, Normal $62,7 \%$ dan status gizi berat badan lebih $11,5 \%$, obese $14,8 \%$ dan prevalensi tertinggi status gizi berat badan lebih dan obese terdapat pada provinsi Sulawesi Utara, dengan $24,1 \%$ pada status gizi obese dan $16,5 \%$ berat badan lebih. (Irza N,R, Dkk, 2018).

Jumlah penduduk lansia untuk Provinsi Sulawesi Utara adalah sebanyak 191,853 jiwa, dari jumlah penduduk sebanyak 2,270,596 jiwa (Profil penduduk 2012 dalam Riskesdas, 2018).

Provinsi Sulawesi Utara pada tahun 2013 terdapat jumlah kasus hipertensi sebanyak 98,07\% kasus dan merupakan urutan kedua dari sepuluh besar penyakit menonjol. Berdasarkan data yang didapat dari Dinas Kesehatan Kabupaten Minahasa tentang 10 penyakit menonjol tahun 2013 hipertensi menempati urutan kedua tertinggi sebanyak 30.168 kasus, dan pada tahun 2014 hipertensi masih menempati urutan kedua tertinggi 10 penyakit menonjol yaitu sebanyak 32.910 kasus. (Rion Adam, Dkk 2015).

Berdasarkan hasil data dari ( BPS) Kabupaten Bolaang Mongondow tahun 2018 bahwa kasus hipertensi tercatat hingga 2267 kasus hipertensi. Dari data status gizi pada tahun 2018 usia $\geq 18$ tahun ke atas yang mengalami berat badan lebih 16,3\%, obesitas 30,22\%. Sedangkan cakupan pelayanan kesehatan usia lanjut menurut jenis kelamin, Kabupaten/Kota Provinsi Sulawesi Utara termasuk di Bolaang Mongondow yaitu lelaki dan perempuan sebanyak 21,079. Demikian data yang diperoleh dari BPS (Badan Pusat Statistik, 2018) Provinsi Sulut.

Sesuai Hasil penelitian yang dilakukan Nonce Nova Legi (2015) Tentang Hubungan Status Gizi Lansia Dengan Hipertensi Di Wilayah Kerja Puskesmas Paniki Bawah Kecamatan Mapanget 
Kota Manado Tahun 2015. Yaitu salah satu faktor yang memicu timbulnya penyakit hipertensi karena status gizi tidak merata. Kelebihan gizi dimulai pada usia 45 tahun hingga biasannya berhubungan gaya hidup dan kemakmuran. Dengan kondisi asupan makanan dan vitamin gizi melebihi kebutuhan tubuh. Situasi kelebihan gizi ini akan membawa situasi obesitas perubahan status gizi ditandai dengan peningkatan berat badan secara lansung mempengaruhi tekanan darah tinggi. Berdasarkan dari Hasil Penelitian, maka dapat menyimpulkan bahwa lansia paling banyak pada kategori gizi normal sebanyak 53 responden $(65,4 \%)$ dan lansia yang tinggal di banyak di prehipertensi terhitung $43 \quad(53,1 \%)$ responden.

Sehubungan Hasil Penelitian yang dilakukan Rion Adam, Dkk (2015) Tentang Hubungan Status Gizi dengan Kejadian Hipertensi Usia 41-65 Tahun di Desa Sinuian Kecamatan Remboken Kabupaten Minahasa Tahun 2015. Yaitu Hipertensi masih menjadi masalah besar diberbagai negara terutama negaranegara yang sudah maju. Penelitian ini bertujuan untuk mengetahui hubungan antara status gizi dengan kejadian hipertensi usia 41-65 tahun di Desa Sinuian Kecamatan Rembekan Kabupaten Minahasa Tahun 2015. Hasil Penelitian menunjukkan bahwa sebanyak $69,3 \%$ responden yang tidak mengalami hipertensi, dan sebanyak $30,7 \%$ responden yang mengalami hipertensi.

Terkait itu juga Hasil Penelitian dari Asrinawaty \& Norvay, 2014 yang menyatakan bahwa ada hubungan antara status gizi dengan kejadian hipertensi lansia diposyandu lansia kakaktua, wilaya kerja puskesmas pelambuan, gizi lebih meningkatkan resiko terjadinya hipertensi. Peneliti yang dilakukan para pakar menunjukkan bahwa masalah gizi pada lansia sebagian besar merupakan masalah gizi yang berlebih yang memicu timbulnya penyakit degeneratif, seperti penyakit jantung koroner, hipertensi, diabetes melitus, batu empedu, rematik, ginjal, sirosis hati, dan kanker. Sedangkan masalah gizi kurang juga banyak terjadi seperti kurang energi kronis, anemia, dan kekurangan zat mikro lain.

Sesuai Hasil Studi Pendahuluan Peneliti Yakni, Pada Tanggal 27 Januari 2020 jumlah lansia yang berumur 60 tahun ke atas di desa Tombolango terdapat 155 jiwa lansia, berdasarkan survey data awal terdapat 10 lansia yang mengikuti posyandu di Desa Tombolango terdapat 8 lansia dengan hipertensi dan 2 diantaranya tidak hipertensi, di dapatkan pula data lansia pada Bulan November 20197 orang Hipertensi, Bulan Desember 20197 orang Hipertensi, dan pada Bulan Januari 20208 orang dengan Hipertensi.

Hasil wawancara kepada 8 lansia yang hipertensi yang sering mengikuti posyandu di Desa Tombolongo Kecamatan Lolak memiliki keluhan melalui hasil pemeriksaan Tekanan Darah, Berat Badan, Tinggi Badan pada lansia. Hasil observasi status gizi, kurang,normal dan lebih pada lansia yaitu 2 lansia yang status gizi kurang terdapat penyakit Ispa, Anemia, dan kurangnya rasa lapar, sedangkan gizi lebih terdapat penyakit hipertensi, asam urat, kolestrol, dan lansia juga mengeluh sulit tidur pada siang hari baik gizi lebih, normal dan kurang. Dan dari 10 lansia yang mengikuti posyandu di desa tombolango kecamatan lolak 7 orang perempuan, 1 laki-laki, yang mengalami hipertensi dan 2 orang perempuan diantaranya yang tidak hipertensi. 
Setelah dilakukan wawancara lansia tersebut mengakui sering mengkomsumsi makanan yang tinggi garam, sering menggunakan penyedap rasa dan santan pada saat memasak, minum kopi, dan sering makan cemilan seperti roti, kue, dll. bukan hanya yang menderita penyakit hipertensi yang tidak hipertensi juga sering mengonsumsi makanan dan minuman di atas. Informasi diatas peneliti tertarik untuk melihat lebih mendalam mengenai Hubungan Status Gizi dengan Derajat Hipertensi Pada Lansia Di Desa Tombolango Kecamatan Lolak.

\section{METODE PENELITIAN}

Penelitian ini merupakan penelitian jenis correlational dengan design cross sectional yang dilakukan di Puskesmas III Denpasar Utara pada bulan uni 2020. Populasi target penelitian ini yaitu 32 pasien atau lansia hipertensi yang melakukan kunjungan pada bulan Oktober 2017. Sampel penelitian adalah 32 lansia hipertensi yang dipilih dengan teknik nonprobability sampling yaitu total sampling. Kriteria inklusi penelitian ini yaitu lansia di atas 60 tahun dan penderita hipertensi. Kriteria eksklusi penelitian ini yaitu memiliki lansia yang berumur dibawah 60 tahun dan yang tidk bersedia menjadi responden.

Instrumen pengumpulan data merupakan alat bantu yang digunakan oleh peneliti untuk kegiatan penelitian pengumpulan data dalam kegiatannya untuk mengumpulkan data agar menjadi kegiatan menjadi dipermudah olehnya dan sistematis menurut (Sujarweni, 2014).

Alat yang akan digunakan peneliti yaitu Alat Sphygmomanometer aneroid dan stetoskop onemed digunakan untuk pengukuran penyakit hipertensi atau penentuan nilai tekanan darah (sistole dan diastole). Pengukuran Antropometri Antropometri dilakukan untuk mengukur Status Gizi lansia dengan menggunakan timbangan dan microtoise.

Pengumpulan data dilakukan dengan memberikan kuesioner di ruang tunggu pengambilan obat puskesmas dengan estimasi waktu 15-20 menit. Data yang terkumpul kemudian ditabulasi ke dalam matriks pengumpulan data yang telah dibuat sebelumnya oleh peneliti dan kemudian dilakukan analisa data.

Uji korelasi yang digunakan dalam penelitian ini yaitu uji Chi Square karena data berbentuk katagorik. Penelitian ini telah mendapatkan surat keterangan laik etik dari Komisi Etik Penelitian Program studi S1 Keperawatan Stikes Graha Medika Kotamobagu.

\section{HASIL PENELITIAN}

Tabel 1 .

Karakteristik Responden Penelitian

\begin{tabular}{cccc}
\hline Variabel & Kategori & $\mathrm{n}$ & $\%$ \\
& $60-65$ & 23 & 71,9 \\
Umur & $66-70$ & 5 & 15,6 \\
& $71-75$ & 4 & 12,5 \\
Jenis Kelamin & Laki-laki & 5 & 15,6 \\
Pekerjaan & & 27 & 84,4 \\
& Petani & 6 & 18,8 \\
Pendidikan & IRT & 26 & 81,2 \\
& SD & 23 & 71,9 \\
& SMP & 9 & 28,1 \\
\hline
\end{tabular}




\begin{tabular}{cccc}
\hline & Kurang & 3 & 9,4 \\
Status Gizi & Normal & 3 & 9,4 \\
& Lebih & 11 & 34,4 \\
Derajat Hipertensi & Obesitas & 15 & 46,9 \\
Lansia & Hipertensi Derajat I & 23 & 71,9 \\
& & 9 & 28,1 \\
\hline
\end{tabular}

Tabel 1 menunjukkan karakteristik responden penelitian. Sebagian besar responden berada pada rentang usia 56-64 tahun yaitu 59\%. Sebagian besar responden berjenis kelamin perempuan yaitu $73,8 \%$. Sebagian besar responden berada pada tingkat pendidikan SD yaitu $26,2 \%$. Seluruh responden tinggal dengan keluarga. Sebagian besar responden terdiagnosis hipertensi $<5$ tahun yaitu $57,4 \%$. Seluruh responden tidak memiliki kebiasaan merokok. Sebagian besar responden tidak memiliki kebiasaan minum kopi yaitu $72,1 \%$. Sebagian besar responden berada pada tekanan darah sistolik pre hipertensi yaitu 50,8\%. Sebagian besar responden berada pada tekanan darah diastolik hipertensi tingkat I yaitu 39,5\%.

Tabel 2.

Status Gizi Lansia

\begin{tabular}{lcc}
\hline \multicolumn{1}{c}{ Status Gizi } & n & \% \\
\hline Kurang & 3 & 9,4 \\
Normal & 3 & 29,5 \\
Lebih & 11 & 34,4 \\
Kurang & 15 & 46,9 \\
\hline Total & $\mathbf{3 2}$ & $\mathbf{1 0 0}$ \\
\hline
\end{tabular}

Pada tabel 2 di atas, 3 Responden (9,4\%) mendapat Status Gizi kurang, 3 Responden $(9,4 \%)$ mendapat status gizi normal, 11 Responden (34,4\%) mendapatkan status gizi Lebih, dan mendapatkan status gizi obesitas sebanyak 15 Responden (46,9\%) dari total 32 responden.

Tabel 3.

Derajat Hipertensi Lansia

\begin{tabular}{lcc}
\hline \multicolumn{1}{c}{ Derajat Hipertensi } & $\mathbf{N}$ & \% \\
\hline Hipertensi Derajat I & 23 & 71,9 \\
Hipertensi Derajat II & 9 & 28,1 \\
\hline Total & $\mathbf{6 1}$ & $\mathbf{1 0 0}$ \\
\hline
\end{tabular}

Berdasarkan tabel 5.6. di atas menunjukkan bahwa yang mengalami Hipertensi Derajat 1 sebanyak 23 orang
$(71,9 \%)$ dan Hipertensi Derajat 2 ada 9 Responden $(28,1 \%)$ dari total 32 Responden. 
Tabel 4

Hasil Analisis Chi Square

Derajat Hipertensi

Pada Lansia

\begin{tabular}{|c|c|c|c|c|c|c|c|c|}
\hline & & \multicolumn{2}{|c|}{$\begin{array}{c}\text { Hipertensi } \\
\text { Derajat } 1\end{array}$} & \multicolumn{2}{|c|}{$\begin{array}{c}\text { Hipertensi } \\
\text { Derajat } 2\end{array}$} & \multicolumn{2}{|c|}{ Total } & \multirow[t]{2}{*}{$P$ Value } \\
\hline & & $\mathrm{N}$ & $\%$ & $\mathrm{n}$ & $\%$ & $\mathrm{~N}$ & $\%$ & \\
\hline $\begin{array}{l}\text { Status } \\
\text { Gizi }\end{array}$ & Kurang & 3 & 9.4 & 0 & 0 & 3 & 9,4 & \\
\hline & Normal & 3 & 9.4 & 0 & 0 & 3 & 9,4 & 0,003 \\
\hline & Lebih & 11 & 34.4 & 0 & 0 & 11 & 34,4 & \\
\hline & Obesitas & 6 & 18.8 & 9 & 28.1 & 15 & 46,9 & \\
\hline Total & & 23 & 71.9 & 9 & 28.1 & 32 & 100 & \\
\hline
\end{tabular}

Berdasarkan Tabel 4 di atas menunjukkan bahwa dari 32 Responden (100\%) didapatkan Status Gizi kurang terdapat 3 orang $(9,4 \%)$ yang mempunyai Hipertensi Derajat 1, Status Gizi Normal 3 orang $(9,4 \%)$ yang mempunyai Hipertensi Derajat 1, Status Gizi Lebih 11 orang (34,4\%) yang mempunyai Hipertensi Derajat 1, dan memiliki Status Gizi Obesitas 15 orang dengan 6 orang $(18,8 \%)$ yang mempunyai Hipertensi Derajat 1 dan Hipertensi Derajat 2, 9 orang $(28,1 \%)$ jumlah Hipertensi Derajat 1 yaitu 23

\section{PEMBAHASAN}

Berdasarkan Hasil Penelitian didapatkan pada lansia yang memiliki Status Gizi berlebih cenderung memiliki tekanan darah tinggi dari pada yang memilki status gizi kurang dan normal. Tetapi pada Status Gizi Kurang, Normal, Lebih dan Obesitas ada yang mengalami Hipertensi Derajat 1 dan Derajat 2 di karenakan salah satu faktor adalah riwayat keluarga, faktor genetik, dan Konsumsi penyedap rasa berlebih dapat menyebabkan hipertensi primer juga dan riwayat keluarga mempunyai resiko yang lebih besar untuk memilki tekanan darah tinggi dibandingkan dengan keluarga tanpa adanya riwayat. Diharapkan lansia dapat menjaga pola makan gizi seimbang serta perlunya dukungan dari pihak keluarga untuk orang $(71,9 \%)$ dan Hipertensi Derajat 2, 9 orang $(28,1 \%)$ total 32 orang.

Hasil analisis Hubungan Status Gizi dengan Derajat Hipertensi Pada Lansia di Desa Tombolango Kecamatan Lolak menggunakan Uji Chi-Square dengan tingkat kepercayaan 95\% ( $\mathrm{a}=$ $0,003)$ didapatkan hasil $\mathrm{P}$ value adalah 0,003 dengan demikian $(0,003<0,005)$, ini berarti Ho di tolak dan Ha di terima, sehingga kesimpulannya yaitu ada Hubungan Status Gizi dengan Derajat Hipertensi Pada Lansia di Desa Tombolango Kecamatan Lolak.

menumbuhkan kesadaran akan pentingnya kesehatan sekaligus mengajak lansia agar dapat memeriksakan kesehatannya ke posyandu teerdekat.

Hasil penelitian yang sama juga didapatkan oleh Hardiani (2019). Dengan judul penelitian "Hubungan IMT Dengan Hipertensi Pada Lansia Di Kelurahan Gayungan Surabaya" Dengan hasil penelitian lansia memiliki IMT terbanyak pada lansia adalah IMT lebih dan IMT Obes 1 yaitu 14 orang (29,8\%). Hasil penelitian yang sama juga di dapatkan oleh Asrinawaty, Norfai (2014). Dengan judul penelitian "Hubungan Status Gizi dengan Kejadian Hipertensi Pada Lansia di Posyandu 
Lansia Kakaktua Kerja Puskesmas Pelabuan" dengan hasil status gizi kurang 13 orang atau $22 \%$, gizi normal 22 orang atau $37,3 \%$, gizi lebih 24 orang $40,7 \%$. Berdasarkan hasil uji statistik yang dilakukan terdapat hubungan yang bermakna antara status gizi dengan kejadian hipertensi pada lansia dengan nilai $\mathrm{p}=$ value $=0,031$.

Menurut Asrinawaty dan Norfai (2014). Status gizi adalah keadaan kesehatan individu-individu atau kelompokkelompok yang ditentukan oleh derajat kebutuhan fisik akan energi dan zat gizi yang diperoleh dari pangan dan makanan yang dampak fisiknya diukur secara antropemetri. Gizi lebih meningkatkan resiko terjadinya hipertensi karena beberapa sebab. Makin besar massa tubuh, makin banyak darah yang dibutuhkan untruk memasok oksigen dan makanan ke jaringan tubuh. Ini berarty volume darah yang beredar melalui pembuluh darah menjadi meningkat sehingga memberi tekanan lebih besar pada dinding arteri, yang akan menimbulkan terjadinya kenaikan tekanan darah.

Menurut Nugraheni, dkk (2019). Kelebihan gizi pada lansia biasanya berhubungan dengan afluenci dan gaya hidup pada usia sekitar 50 tahun. Kondisi ekonomi yang semakin membaik dan tersediannya berbagai makanan saji yang enak dan kaya energi, utamanya dari sumber lemak, terjadi asupan makanan dan zat-zat gizi melebihi kebutuhan tubuh. Gizi yang dimulai pada awal usia 50 tahunan ini akan membawa lansia dalam keadaan obesitas dan dapat pula disertai penyakit metabolisme.

Berdasarkan tabel 5.6. di atas menunjukkan bahwa yang mengalami Hipertensi Derajat 1 sebanyak 23 orang $(71,9 \%)$ dan Hipertensi Derajat 2 ada 9
Responden $(28,1 \%)$ dari 32 Responden. Peneliti lebih memprioritaskan untuk mengetahui sebaran derajat hipertensi disubjek peneliti yang akan digunakan sebagai dasar tindak lanjut dari penelitian ini, misalnya pemberian penyuluhan kesehatan tentang pencegahan hipertensi melalui pengendalian faktor resiko hipertensi.

Berdasarkan Hasil Penelitian yang didapatkan bahwa sebagian besar lansia yang mempunyai hipertensi derajat 1 dengan tekanan darah diatas 140/80 mmHg lebih banyak dengan jumlah 23 responden $(71,9 \%)$ dibandingkan dengan derajat 2 160/100 $\mathrm{mmHg}$ dengan jumlah 9 responden $(28,1 \%)$ di karenakan lansia cenderung atau resiko terkena hipertensi karena faktor usia, juga keturunan dan gaya hidup tidak sehat. Banyak orang yang sudah meninggalkan budaya makan di Indonesia seperti meninggalkan makanan tradisional dan berahli ke makanan siap saji dan kaya lemak, yang ternyata tidak sehat serta miskin kandungan gizi dibandingkan makanan tradisional yang kita miliki. Ini yang mengakibatkan berbagai penyakit metabolik seperti hipertensi.

Hasil penelitian yang didapatkan oleh Ratnaningrum (2015) dengan Hubungan Asupan Serat dan Status Gizi dengan Tekanan Darah Pada Wanita Menopause di Desa Kuwiran Kecamatan Banyudono Kabupaten Bayoyali yaitu menunjukkan distribusi tekanan darah subjek yang termasuk dalam ketegori tekanan darah normal yaitu sebanyak 20 orang $(27,4 \%)$ dan subjek yang memiliki kategori tekanan darah darah tinggi yaitu sebanyak 53 orang $(72,6 \%)$. Tekanan darah merupakan faktor yang berperan penting di dalam sistem sirkulasi tubuh. Naik atau turunnya tekanan darah dapat mempengaruhi keseimbangan di dalam tubuh. 
Menurut Rahayu, dkk (2020). Resiko terkena hipertensi dengan berat badan lebih, berpeluang 2,3 kali dibandingkan dengan berat badan normal dan kurus. Responden dengan berat badan lebih akan terjadi penumpukan jaringan lemak, yang dapat menyebabkan peningkatan resistensi pembuluh darah dalam meningkatkan kerja jantung untuk dapat memompakan darah ke seluruh tubuh.

Hipertensi adalah keadaan peningkatan tekanan darah yang memberi gejala yang akan berlanjut ke suatu organ target seperti stroke, penyakit jantung koroner, dan hipertrofi ventrikel kanan, dengan target organ di otak yang berupa stroke. Hipertensi menjadi penyebab utama stoke yang membawa kematian yang tinggi (Bustan,2007 dalam Asrinawaty dan Norfai 2014). Menurut WHO, tekanan darah seseorang dikatakan normal jika sistoliknya kurang dari 140 $\mathrm{mmHg}$ dan diastoliknya kurang dari 90 $\mathrm{mmHg}$, jika sistolik di antara 140-160 $\mathrm{mmHg}$ dan diastolik di antara 90-95 $\mathrm{mmHg}$ disebut bordreline hypertension yang pada posisi ini seseorang harus waspada karena memiliki kecenderungan kuat mengidap hipertensi, apabila seseorang memiliki sistolik lebih dari $160 \mathrm{mmHg}$ dan diastolik lebih dari $95 \mathrm{mmHg}$ maka jelas orang tersebut mengidap hipertensi (Elisa,2008 dalam Asrinawaty dan Norfai 2014).

Berdasarkan hasil penelitian dari total 32 responden dengan menggunakan analisa data dengan tingkat kepercayaan 95\% $(0,05)$ didapatkan hasil $\mathrm{P}$ value adalah 0,003 dengan demikian $(0,003<0,05)$, maka dapat disimpulkan bahwa ada Hubungan antara Status Gizi dengan Derajat Hipertensi Pada Lansia di Desa Tombolango Kecamatan Lolak.
Hal ini dapat diartikan bahwa lansia yang memilki Status Gizi yang Lebih 11 Orang 34,4\% dan Obesitas 15 orang $46,9 \%$ dapat memicu terjadinya Darajat Hipertensi Pada Lansia di Desa Tombolango.

Berdasarkan hasil penelitian ini, maka peneliti berasumsi bahwa Status Gizi dapat mempengaruhi Hipertensi karena faktor pencetus yaitu Obesitas atau berat badan berlebih sehingga yang banyak menderita Hipertensi Derajat 1 di bandingkan Hipertensi Derajat 2.

Penelitian ini sejalan dengan penelitian yang dilakukan oleh Legi (2015) yang menyatakan bahwa terdapat Hubungan Status Gizi Lansia dengan Hipertensi di Wilayah Kerja Puskesmas Paniki Bawah Kecamatan Mapanget Kota Manado Tahun 2015.Yaitu salah satu faktor yang memicu timbulnya penyakit hipertensi karena status gizi tidak merata. Kelebihan gizi dimulai pada usia 45 tahun hingga biasannya berhubungan gaya hidup dan kemakmuran. Dengan kondisi asupan makanan dan vitamin gizi melebihi kebutuhan tubuh. Situasi kelebihan gizi ini akan membawa situasi obesitas perubahan status gizi ditandai dengan peningkatan berat badan secara lansung mempengaruhi tekanan darah tinggi dan menunjukkan bahwa ada hubungan status gizi lansia dengan hipertensi di Wilayah Kerja Puskesmas Paniki Bawah Kecamatan Mapanget Kota Manado Tahun 2015 dengan nilai $\mathrm{P}$ $=$ value 0,000 .

Hasil penelitian sejalan juga dengan dilakukan oleh Fitriana (2015) yang menyatakan bahwa Hubungan Antara Status Gizi dengan Kejadian Hipertensi di Posyandu Lansia Wilayah Kerja Puskesmas Wuluhan Kabupaten Jember tahun 2015, menunjukkan bahwa ada 
Hubungan Status Gizi dengan Hipertensi Pada Lansia.

Menurut Beck dalam Fitriana (2015). Obesitas merupakan faktor resiko utama terjadinya penyakit kardiovaskuler, data secara konsisten menunjukkan peningkatan insidensi penyakit seiring dengan meningkatnya IMT (Indeks Massa Tubuh). Obesitas juga merupakan faktor resiko bagi sejumlah kondisi kesehatan lain yang terkait dengan penyakit kardiovaskuler, yakni diabetes melitus tipe 2, dislipidemia, dan hipertensi. Selain itu, menurut Depkes RI, Resiko untuk menderita hipertensi pada orang dengan berat badan berlebih 5 kali lebih tinggi dibandingkan dengan orang yang berat badan normal. Berdasarkan hasil penelitian sebelumnya yang telah banyak dilakukan, membuktikan adanya korelasi yang positif antara status gizi dengan kejadian hipertensi pada lansia. Hal ini sebabkan karena mereka suka mengkonsumsi makanan tinggi lemak yang berkaitan pada kenaikan berat badan tanpa diimbangi dengan aktiifitas fisik yang rutin.

Namun hasil penelitian ini tidak sejalan dengan yang di lakukan oleh Miranda (2019) yang diperoleh nilai $\mathrm{p}=0,172$ yang menunjukkan bahwa tidak ada hubungan dimana hipertensi tidak hanya disebabkan oleh status gizi, bisa juga karena faktor lain seperti kebiasaan pola makan yang sering mengkomsumsi sumber makanan tinggi natrium dan lemak, mempunyai riwayat keluarga hipertensi, faktor stress, rokok, dll.

Hasil penelitian juga tidak sejalan yang dilakukan oleh Sariyanti dkk (2019) yang menyatakan bahwa Hubungan Pendapatan Antara Status Gizi dengan
Derajat Hipertensi di Indonesia Tua, yang diperoleh nilai $p$ value $p=0,640$ yang menunjukkan bahwa tidak ada hubungan lansia yang memiliki status gizi baik atau tidak resiko yang sama yang mengalami hipertensi. Salah satu faktor seseorang yang menderita hipertensi adalah status gizi yang tidak seimbang. Lebih besar semakin banyak massa tubuh, semakin banyak darah yang dibutuhkan suplai oksigen dan makanan.

Penelitian ini tidak sejalan dengan dilakukan oleh Ratnaningrum (2015) dengan judul Hubungan Asupan Serat dan Status Gizi dengan Tekanan Darah Pada Wanita Menopause di Desa Kuwiran Kecamatan Banyudono Kabupaten Bayoyali. Menunjukkan hasil analisis dengan menggunakan uji ChiSquare pada uji hubungan status gizi dengan tekanan darah diperoleh nilai $\mathrm{p}$ value sebesar $0,412 \quad(p \geq 0,05)$ yang artinya tidak ada hubungan antara status gizi dengan tekanan darah pada wanita menopause di Desa Kuwiran Kecamatan Banyudono Kabupaten Boyolali.

Peneliti berasumsi bahwa kelebihan gizi atau status gizi yang lebih dapat berdampak buruk terhadap kesehatan seseorang seperti halnya dengan obesitas. Obesitas salah satu faktor pencetus hipertensi karena seseorang yang mengalami peningkatan berat badan lebih sehingga bisa menyebabkan hipertensi. Faktor lain yang berhubungan dengan hipertensi seperti gaya hidup, asupan garam, genetik serta stress, gaya hidup pola makan yang berlebih juga dapat meningkatkan tekanan darah terlebih.

\section{KESIMPULAN DAN SARAN}


Status gizi lansia di Desa Tombolango Kecamatan Lolak dengan frekuensi 3 orang atau 9,4\% mendapatkan Status gizi yang Kurang dan 3 orang atau 9,4\% mendapatkan Status gizi Normal dan 11 orang atau 34,4\% mendapatkan Status gizi lebih dan paling banyak 15 orang atau 46,9\% mendapatkan Status gizi Obesitas. Derajat Hipertensi Pada Lansia di Desa Tombolango Kecamatan Lolak 32 orang sebanyak 23 Responden atau $71,9 \%$ yang mengalami Hipertensi derajat 1 lebih banyak dari pada Responden yang mengalami hipertensi derajat 2 yaitu 9 responden atau $28,1 \%$. 7.1.3. Berdasarkan 32 Responden (100\%) didapatkan Status Gizi kurang terdapat 3 orang $(9,4 \%) \quad$ yang mempunyai hipertensi derajat 1 , Status gizi normal 3 orang $(9,4 \%)$ yang mempunyai hipertensi derajat 1 , status gizi lebih 11 orang $(34,4 \%)$ yang mempunyai hipertensi derajat 1 , dan memiliki status gizi obesitas 15 orang dengan 6 orang $(18,8 \%)$ yang mempunyai hipertensi derajat 1 dan hipertensi derajat 2,9 orang $(28,1 \%)$ jumlah hipertensi derajat 1 yaitu 23 orang $(71,9 \%)$ dan hipertensi derajat 2, 9 orang $(28,1 \%)$ total 32 orang. Hasil penelitian ini diperoleh nilai $p=0,003$ hasil analisis menunjukkan ada hubungan yang signifikan antara Status gizi dengan Derajat Hipertensi lansia.

\section{DAFTAR PUSTAKA}

Asrinawati, \& Norfai, (2014). Hubungan Status Gizi Dengan Kejadian Hiperetensi pada Lansia Di Posyandu Lansia KakakTua di Wilayah Kerja Puskesmas Pelambuan. Fakultas Kesehatan Masyarakat, UNISKA.

Adam, R \& Punuh,M, I, Kapantau, N, H . (2015). Jurnal Hubungan Antara Status Gizi Dengan Kejadian Hiprtensi Usia 41-65 Tahun Di Desa Sinuian.
Penelitian ini dapat menjadi referensi dan daftar pustaka untuk peneliti selanjutnya diharapkan dapat melanjutkan penelitian dengan jumlah sampel yang lebih dengan metodelogi lain agar melakukan penelitian lebih mendalam terkait derajat hipertensi pada lansia agar bisa dijadikan sumber pengetahuan baru, Menjaga pola makan dengan gizi seimbang ataupun makan lebih banyak sayur dan buahnya dari pada karbohidrat untuk mengendalikan status gizi.

Mengurangi Konsumsi baik minuman atau makanan yang menyebabkan tekanan darah meningkat seperti mengurangi konsumsi minuman yang mengandung soda dan alkohol serta makanan yang mengandung banyak garam. Menganjurkan untuk selalu kontrol secara rutin dan memantau tekanan darah bagi lansia yang mempunyai riwayat penyakit keluarga hipertensi serta memperhatikan pola makan sejak dini. Semoga penelitian ini dapat menjadi tambahan ilmu pengetahuan dalam mengembangkan ilmu mengenai Status gizi dengan derajat hipertensi pada lansia dan bisa mengaplikasikan kepada masyarakat seperti pemberian edukasi. Bahan untuk lebih meningkatkan motivasi kerja perawat dalam memberikan pelayanan kesehatan khususnya pada masyarakat yang mengalami hipertensi.

Alfeus M, (2018). Terapi Perilaku Kognitif Pada Pasien Hipertensi. Penerbit Wineka Media

Bustan, M, 2016. Epidemiologi Penyakit Tidak Menular, Jakarta Rineka.

Dinkes Kab Bolaang Mongondow Induk, 2018. Laporan Posbindu Penyakit Tidak Menular (PTM).

Donsu,J,D, T, (2017). Metodologi Penelitian Keperawatan. Yogyakarta : Pustaka Baru Press. Fitriana, R (2015). Hubungan antara konsumsi makanan dan status gizi dengan kejadian 
hipertensi pada lansia di posyandu lansia wilayah kerja puskesmas wuluhan kabupaten jember. Universitas Jeber.

Febriani, K \& Rachmiani, I (2017). Jurnal Hubungan Status Gizi Dan Insomnia Dengan Kejadian Hipertensi Pada Pria Lanjut Usia Produktif. Universitas Trisakti.

Festi, P, (2018). Buku Ajar Gizi Dan Diet. Surabaya :UMSurabaya Publishing

Kholifa, S, N, (2016). Keperawatan Gerontik, Cetakan pertama

Mardalena, I, (2017). Dasar-Dasar Ilmu Gizi. Yogyakarta : Pustaka Baru Press.

Herdiani,N (2016). Hubungan IMT Dengan Hipertensi Pada Lansia Di Kelurahan Gayungan Surabaya. Di unduh tgl 15 juli 2020.

Nursalam, (2013) . Metodologi Penelitian Ilmu keperawatan. Jakarta : salemba medika.

Nugraheni, dkk (2019). Jurnal Hubungan Berat Badan dan Tekanan Darah Pada Lansia. Universitas Sebelas Maret.

Nur, A,Darwin, K, \& Fatrha, A,N (2018). Jurnal Gambaran Kualitas Hidup Lansia Dengan Hipertensi Di Wilayah Kerja Puskesmas Sidomulyo Kecamatan Tampan Pekanbaru.Universitas Riu.

Pratiwi, E, \& dr. Yekti, M, (2017). Tetap Sehat Saat Lansia- Pencegahan dan penanganan 45 penyakit yang Sering Hinggap Di Usia Lanjut. Yogyakarta : Rapha Publishing.

Padila, (2013). Buku ajar Keperawatan Gerontik. Yogyakarta : Nuha Medika.

Profil Kesehatan Kab/Kota Prov. Sulut Tahun 2017.

Piyanit Churak, dkk (2018). Jurnal factor associated with nutritional status of elderly in ubon ratchathani, Thailand. Instituti of Nutrition, mahidol university, salaya, phutthamonthon, nakhon pathom, Thailand. Di unduh 16 Mei 2020.

Riskesdas, (2018). Kementriaan Kesehatan Badan Penelitian dan Pengembangan Kesehatan. Di Unduh 26 januari 2020
Rahayu, dkk (2020). Jurnal Hubungan Obesitas dengan Hipertensi Pada Pra Lansia di Puskesmas Sukamulya Tahun 2019.Universitas Respati Indonesia

Ratnawati, E, (2017). Asuhan keperawatan gerontik. Yogyakarta : Pustaka baru.

Ratnaningrum,Y,S,P,D (2015). Jurnal Hubungan Asupan Serat Dan Status Gizi Dengan Tekanan Darah Pada Wanita Menopause Di Desa Kuwiran Kecamatan Banyudono Kabupaten Bayolali. Universits Muhammadiyah Surakata. Di Unduh 19 Juli 2020.

Setyawati,V, A, V, \& Hartini, E, (2018). Buku Ajar DASAR Ilmu Gizi Kesehatan Masyarakat. Yogyakarta : Deepublish, CV Budi Utama.

Suiraoka, I, (2013). Penyakit Degeneratif . Yogyakarta : Nuha Medika.

Swarjana, I, K, (2015). Metodologi Penelitian Kesehatan .Yogyakarta :Perpustakaan Nasional.

Sujarweni, ,V, W. (2014). Metode Penelitian Keperawatan. Yogyakarta : Gava Media,

S. A. Deji, (2014). Jurnal Assessment of nutritional status of a group of hypertensive patients attendding tertiary healthcare facilities in nigeria. University Ad0-Ekiti, Nigeria. Di unduh 16 Mei 2020.

Susila \& Suyanto (2015). Metodologi penelitian Cross Sectional.Klaten : perpustakaan nasional

Sariyanti N,E, dkk (2020). The relationship between income and nutritional status with the incidence of hypertension in elderly. Di unduh 19 Juli 2020.

Venny R, P, Zaimah Z. T, (2013) . Jurnal Gambaran Status Gizi Pasien Hipertensi Lansia Di RSUP H. Adam Malik Medan.

Yulianti, S \& Rokhanawari, D, Yuli I,( 2010). Jurnal Hubungan Status Gizi Dengan Kejadian Hipertensi Pada Wanita Lanjut Usia Di Posyandu Wira Lestari 6 Wirobrajan Yoyakarta 